\title{
Perioperative Factors Influencing Postoperative Satisfaction After Lateral Access Surgery for Degenerative Lumbar Spondylolisthesis
}

\author{
SHENG XU, MBBS, MRCS, MING HAN LINCOLN LIOW, MBBS, DFD, MRCS, MMED, KENG MENG \\ JEREMY GOH, MBBS, WILLIAM YEO, ZHIXING MARCUS LING, MBBS, MRCS, MMED, FRCS, CHEE \\ CHEONG REUBEN SOH, MBBS, MRCS, MMED, FRCS, SEANG BENG TAN, MBBS, MMED, FRCS, FRCS, \\ FAMS, LI TAT JOHN CHEN, MBBS, BAO, LRCSI, FRCS, CHANG MING GUO, MBBS, MMED, FRCS, \\ FAMS \\ Department of Orthopaedic Surgery, Singapore General Hospital, 20 College Road, Academia, Level 4. Singapore
}

\begin{abstract}
Background: Lateral access surgery (LAS) for lumbar degenerative spondylolisthesis is a minimally invasive lumbar fusion technique which has been gaining increasing popularity in the recent years. This study aims to identify perioperative factors that influence postoperative satisfaction after LAS for lumbar degenerative spondylolisthesis.

Methods: From August 2010 to November 2014, 52 patients with lumbar degenerative conditions (16 male: 36 female, mean age $64.0 \pm 8.7$ years) were prospectively recruited and underwent LAS by a single surgeon. All patients were assessed preoperatively and 2 years postoperatively with Numerical Pain Rating Scale (NPRS), Oswestry Disability Index, Short-Form 36 (SF-36) scores, North American Spine Society score for neurogenic symptoms, patient satisfaction, and expectation fulfillment. Cobb angles, global lumbar lordosis, disc heights, adjacent disc heights, fusion, and subsidence were rates assessed. Multiple linear regression performed with satisfaction as dependent variable to identify predictive independent variables.

Results: Lower preoperative SF-36 general health scores $(P=.03)$, higher NPRS leg pain scores $(P=.04)$, and longer surgical duration $(P=.02)$ were significant predictors of lower satisfaction $(P<.05)$. NPRS back and leg pain decreased by 80.3 and $83.0 \%$, respectively. Oswestry Disability Index and North American Spine Society score for neurogenic symptoms improved by 76.2 and $75.9 \%$, respectively. Ninety percent of patients reported excellent/good satisfaction. Significant correction and maintenance of Cobb and global lumbar lordosis angles were achieved. There was significant increase in disc heights postoperatively $(P=.05)$ and no significant difference in adjacent disc heights at 2 years $(P>.05)$. Ninety-eight percent of patients achieved Bridwell Fusion Grade 1, and 5.8\% had Marchi Grade 3 subsidence.
\end{abstract}

Conclusions: Lower preoperative SF-36 general health, higher NPRS leg pain, and longer surgical duration are predictors of lower satisfaction in patients undergoing LAS for lumbar degenerative spondylolisthesis.

Level of Evidence: III.

Clinical Relevance: Identifying preoperative predictors for postoperative clinical outcome can assist clinicians in patient education prior to operation.

Minimally Invasive Surgery

Keywords: lateral access surgery, minimally invasive surgery, perioperative factors, outcome, spondylolisthesis, spine surgery

\section{INTRODUCTION}

Lateral access surgery (LAS) for lumbar degenerative spondylolisthesis is a minimally invasive lumbar fusion technique which has been gaining increasing popularity in recent years. ${ }^{1}$ First described by Pimenta ${ }^{2}$ in 2001 and modified by Ozgur et al. ${ }^{3}$ in 2006, it allows for anterior access to the disc space without the dreaded complications associated with traditional open anterior or poste- rior surgical approaches. Anterior surgery has been associated with complications such as injuries to the great vessels, retrograde ejaculation, postoperative colonic obstruction, lymphocele formation, or injuries to the sympathetic chain, ${ }^{4-6}$ while posterior surgery has been associated with dural tears, paraspinal muscle denervation, and neural complications such as radiculitis from malpositioned screws or traction during surgery. ${ }^{7-10}$ 
LAS for lumbar degenerative spondylolisthesis has proven to be a safe and efficacious alternative with less postoperative complications, resulting in shorter hospital stay and lower average cost for patients. ${ }^{1-14}$ Its efficacy and safety has also been reproducible across different patient demographics, such as the obese ${ }^{15}$ and the elderly. ${ }^{16}$ These benefits have led to an increase in its utilization by spine surgeons in the management of lumbar degenerative spondylolisthesis. ${ }^{17-20}$ The role of LAS is also expanding, with surgeons exploring its use in osteomyelitis/discitis and even pathological fractures. ${ }^{21}$ In addition, high satisfaction rates of up to $93 \%$ have been reported in minimally invasive LAS. $^{22}$

However, LAS has its own share of complications. Due to the proximity of the lumbar plexus to the approach zone in lateral surgery, motor deficits from injury to nerve roots, particularly in patients treated at the L4 to L5 region, have been reported with an incidence of 0.6 to $3.4 \% .^{23,24}$ Ureteral and vascular injuries have also been reported after LAS in 2 to $4 \%$ of cases. ${ }^{25,26}$ Postoperative thigh pain and hip flexor weakness due to direct trauma to the psoas muscle is also another common complication that can lead to decreased satisfaction postoperatively. $^{24}$

With all the well-described benefits of LAS for lumbar degenerative spondylolisthesis, there is, however, a paucity of literature describing preoperative factors which may influence postoperative satisfaction. An understanding of preoperative factors can allow surgeons to perform individualized preoperative counseling, enable better management of patient expectation, and better patient selection. There have been studies that attempt to identify such predictors for the surgical management of lumbar spinal stenosis. ${ }^{27,28}$ The aim of our study is to identify the perioperative factors that may influence the postoperative satisfaction after LAS for lumbar degenerative spondylolisthesis.

\section{MATERIAL AND METHODS}

\section{Study Design}

This is a retrospective observational study with prospectively collected data. Local institutional review board waiver was obtained for this study. From 1 August 2010 to 30 November 2014, 52 consecutive patients with adult lumbar degenerative conditions underwent LAS spinal decompression and fusion by a single surgeon at our institution. All 52 patients were prospectively followed up. Length of operation and length of stay were recorded, and all patients were assessed preoperatively and at 2 years postoperatively by an independent health care professional not involved in this study. LAS was performed on patients who had failed a trial of conservative treatment (physiotherapy, analgesia, and activity modification) for at least 6 months without significant symptom relief.

\section{Surgical Indications and Surgical Technique}

The inclusion criteria for this study was (1) presence of symptomatic, Grade 1-2 lumbar degenerative spondylolisthesis affecting 1-2 lumbar spinal levels, demonstrated on preoperative flexion/ extension radiographs and/or (2) the presence of multilevel adult degenerative scoliosis with symptomatic lumbar spinal stenosis. Indirect decompression was accomplished through lateral access surgical approach. Patients with acute spinal trauma, spinal infections, spinal tumor, and previous spinal instrumentation were excluded. The CoRoent Lateral Interbody $\left(\mathrm{XLIF}^{\circledR}\right)$ cage and Spherx $^{\mathrm{TM}}$ DBR $^{\mathrm{TM}}$ pedicle screws (NuVasive, San Diego, CA) were used in all surgeries. Pedicle screws were inserted with the aid of neuromonitoring and image intensifier guidance. The patients were positioned in a lateral position, and the midposition of the disc of interest was identified using fluoroscopy. A small incision was made in the lateral flank and upon identification of the retroperitoneal space; blunt dissection of the psoas muscle was achieved with the use serial dilator retractors. Real-time electromyographic monitoring was employed to direct the safe passage through the psoas muscle, avoiding the nerves of the lumbar plexus. A thorough discectomy, end-plate preparation, and release of the contralateral annulus was performed through the illuminated dilator retractors. The implanted cage was positioned to rest on the epiphyseal rings to restore height, maximize stability, and correct coronal/sagittal alignment as necessary. INFUSE ${ }^{\circledR}$ bone morphogenetic protein (Medtronic, Memphis, TN) and FormaGraft (NuVasive, San Diego, CA) were used in the cage/disc space to achieve fusion. Patients were turned to the prone position after cage insertion, and posterior minimally invasive pedicle screw instrumentation was performed for all levels. Hemostasis and wound 
irrigation were performed prior to wound closure. Postoperative rehabilitation was in accordance with our institution's standardized lumbar spine surgery integrated care pathway.

\section{Outcome Assessment Using Clinical, Patient- Reported and Health-Related Quality-of-Life Outcome Measures}

Preoperative patient demographic data including age, gender, and body mass index were recorded. During each visit, validated spine-specific outcome measures, including the Numerical Pain Rating Scale (NPRS) for back and leg pain, Oswestry Disability Index (ODI), Short-Form 36 (SF-36) scores, and the North American Spine Society (NASS) lumbar spine outcome instrument for neurogenic symptoms (NS), and patient-rating for overall result of surgery (patient satisfaction) were recorded.

The 11-item NPRS is a validated Likert scale used specifically to score pain experienced by patients in the back and lower limb. NPRS has shown to be highly correlated with the Visual Analogue Scale with high test-retest reliability in both literate and illiterate patients ${ }^{29}$ and preferred by chronic pain patients due to its comprehensibility and ease of completion. ${ }^{30}$ The ODI is a patientcompleted questionnaire which gives a subjective percentage score of level of function in 10 activities of daily living in those with lower back pain. The ODI addresses a broader concept of disability that is not directly related to pain intensity. ${ }^{31}$ Furthermore, its sensitivity as a measure of change following treatment has been validated. ${ }^{32}$

SF-36 scores, which include the Physical Component Score and Mental Component Score, were used to evaluate the quality of life of patients. NASS lumbar spine outcome assessment instrument ${ }^{33}$ measuring NSs and satisfaction were also evaluated. These tests have proven to have high internal consistency, test-retest reliability, and good validity in distinguishing operative success from operative failure.

At 2 years postoperatively, patient satisfaction of surgery was recorded as part of the NASS questionnaire Question 53. This was graded on a 6-point Likert scale, with a score of 1 indicating an excellent score and a score of 6 representing a terrible score. Satisfaction was also stratified into excellent, good, fair, and poor.

\section{Radiological Outcomes}

All patients underwent a preoperative assessment involving a detailed neurological examination and radiological imaging, including static (anteroposterior and lateral) and dynamic (flexion and extension) plain lumbar spine radiography and magnetic resonance imaging. Radiographs were repeated at 2 years. Cobb angles and global lumbar lordosis were recorded for each patient. Disc heights $(\mathrm{DH})$ and adjacent-level disc heights (ADH) were measured on lateral radiographs for all LAS levels. Based on the levels of LAS performed, mean values of $\mathrm{DH}$ and ADH were calculated for each patient. Subsidence was calculated using mean $\mathrm{DH}$ and classified according to the grading system proposed by Marchi et al. ${ }^{34}$ Fusion rates based on the grading system by Bridwell et al. ${ }^{35}$ were assessed at 2 years. All radiological measurements were performed by 2 orthopaedic residents, on separate occasions, at least 1 week apart, using standardized radiographs.

\section{Statistical Analysis}

All continuous data were expressed in terms of mean and standard deviation of mean. Paired Student's $t$ test was used to compare parametric data and determine differences between preoperative and postoperative time intervals. One-way analysis of variation was used to compare parametric radiological data between preoperative, immediate postoperative, and at 2 years. Multiple linear regression was performed with satisfaction as the dependent variable to identify predictive independent variables. Statistical analysis was performed using SPSS 22.0 software (SPSS Inc, Chicago, IL).

\section{RESULTS}

There were a total of 16 male and 36 female patients, with a mean age of $64.0 \pm 8.7$ years. Sixteen patients underwent LAS lumbar fusion at 1 level, 18 at 2 levels, 17 at 3 levels, and 1 patient at 4 levels. Patients with 3- and 4-level fusions had a combination of degenerative spondylolisthesis and degenerative scoliosis, with listhesis in both the sagittal and coronal planes. Mean operating time was $208.0 \pm 85.1$ minutes, and mean length of stay was $5.0 \pm 2.7$ days. Patient demographics are detailed in Table 1.

There was a positive improvement in pain reduction in our cohort of patients. Mean NPRS back and leg pain decreased significantly at 2 years. 
Table 1. Patient demographics.

\begin{tabular}{lc}
\hline & XLIF $(\mathbf{n}=\mathbf{5 2})$ \\
\hline Age, $\mathrm{y}$ & $64.0 \pm 8.7$ \\
Gender, n (\% male) & $16(30.8 \%)$ \\
Body mass index, kg/m ${ }^{2}$ & $26.2 \pm 4.2$ \\
Duration of surgery, min & $208.0 \pm 85.1$ \\
Length of stay, d & $5.0 \pm 2.7$ \\
XLIF levels, n (\%) & $16(30.8 \%)$ \\
1 & $18(34.6 \%)$ \\
2 & $17(32.7 \%)$ \\
3 & $1(2.0 \%)$ \\
4
\end{tabular}

Abbreviation: XLIF, extreme lateral interbody fusion.

Mean ODI and NASS NS scores improved significantly at 2 years. Significant improvements in SF36 health-related quality-of-life scores were experienced by all patients (Table 2), with 90.3\% (47/52) reporting excellent/good satisfaction scores with their surgical procedure at 2 years. Improvement in outcome measures in all patients from preoperative to 2 years postoperatively attained minimal clinically important difference (ODI of 12.8 points, NPRS back pain of 1.2 points, NPRS leg pain of 1.6 points, and Physical Component Score of 4.9 points $^{36}$ ).

One patient required wound debridement for a superficial wound site infection. Two patients had progression of disease at the caudal L5/S1 level which required an additional fusion procedure. No visceral, vascular, or neurological complications were noted.

Improvements in segmental Cobb angles and global lumbar lordosis were observed, with a significant correction in postoperative Cobb angle

Table 2. Clinical, patient-reported and health-related quality-of-life outcome measures.

\begin{tabular}{lccc}
\hline & $\begin{array}{c}\text { Preoperative } \\
(\mathbf{n}=\mathbf{5 2})\end{array}$ & $\begin{array}{c}\mathbf{2} \text { Years } \\
(\mathbf{n}=\mathbf{5 2})\end{array}$ & $\boldsymbol{P}$ Value \\
\hline NPRSBP & $4.0 \pm 3.3$ & $1.7 \pm 3.0$ & $<.0 \mathbf{0 5}^{\mathrm{a}}$ \\
NPRSLP & $3.3 \pm 3.4$ & $1.2 \pm 2.8$ & $<.05$ \\
ODI & $52.1 \pm 16.8$ & $15.7 \pm 17.8$ & $<.05$ \\
AAOS-NS & $41.4 \pm 24.2$ & $10.9 \pm 17.2$ & $<. \mathbf{0 5}$ \\
SF-36 physical function & $42.2 \pm 27.3$ & $74.8 \pm 23.9$ & $<.05$ \\
SF-36 role physical & $10.5 \pm 27.2$ & $65.2 \pm 41.0$ & $<.05$ \\
SF-36 bodily pain & $27.0 \pm 19.0$ & $65.8 \pm 30.8$ & $<.05$ \\
SF-36 general health & $63.5 \pm 23.0$ & $68.7 \pm 20.2$ & .06 (n.s.) \\
SF-36 vitality & $66.5 \pm 23.8$ & $70.8 \pm 18.4$ & .19 (n.s.) \\
SF-36 social function & $50.7 \pm 36.2$ & $85.6 \pm 29.0$ & $<.05$ \\
SF-36 role emotional & $71.2 \pm 45.7$ & $92.8 \pm 24.3$ & $<.05$ \\
SF-36 mental health & $77.5 \pm 16.7$ & $84.3 \pm 13.5$ & $<.05$ \\
SF-36 PCS & $30.1 \pm 10.5$ & $47.6 \pm 11.4$ & $<.05$ \\
SF-36 MCS & $49.7 \pm 10.9$ & $53.8 \pm 9.5$ & $<.05$ \\
\hline
\end{tabular}

Abbreviations: NPRBP, numerical pain rating scale on back pain; NPRSLP, numerical pain rating scale on lower limb pain; ODI, Owestry disability index; AAOS-NS, American Academy of Orthopaedic Surgeons neurogenic symptoms; n.s., not significant; SF-36 PCS, Short-Form 36 Physical Component Score; SF36 MCS, Short-Form 36 Mental Component Score.

${ }^{\mathrm{a}}$ Boldface denotes values with statistical significance $(P<.05)$.

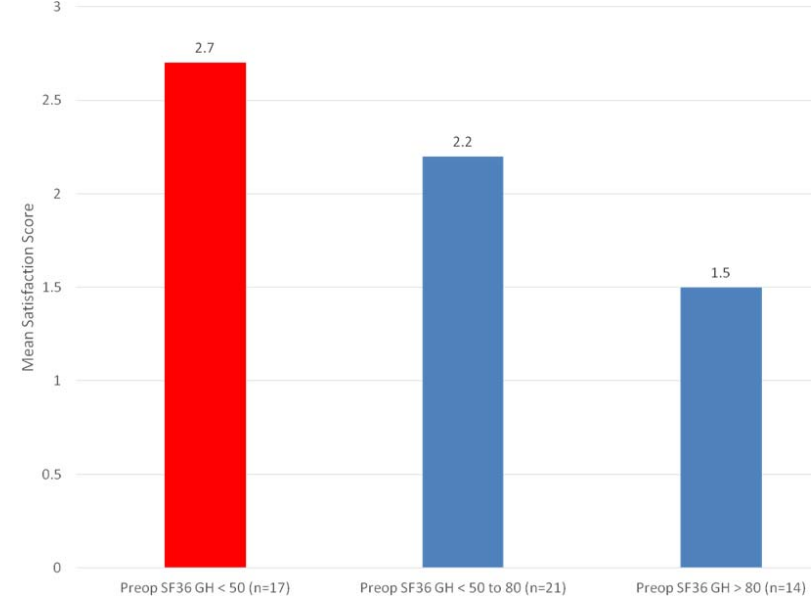

Figure 1. Preoperative Short-Form 36 general health and satisfaction.

$(P<.05)$. Maintenance of Cobb angle and global lumbar lordosis angles were noted at 2 years follow up. Significant increase in mean DH was observed postoperatively which demonstrated minimal subsidence at 2 years. There was no significant difference in the mean $\mathrm{ADH}$ at 2 years, suggesting the absence of early adjacent segment degeneration. Ninetyeight percent of patients achieved mean Grade 1 fusion, however, approximately $70 \%$ had cage subsidence (Grades I to III). Radiological outcomes, grades of subsidence, and fusion rates are detailed in Table 3.

Three significant predictors of lower satisfaction were identified: lower preoperative SF-36 general health scores $(P=.03)$, higher NPRS leg pain score $(P=.04)$, and longer surgical duration $(P<.05$; Figures 1 to 3$)$. Lower satisfaction could be predicted by a linear combination of these 3 factors, which demonstrated moderate correlation with lower satisfaction $(R=0.580)$. There was no significant correlation between NPRS back pain, radiological parameters, grade of subsidence and fusion rate.

\section{DISCUSSION}

The most important finding of this study is the identification of 3 potential predictors that may influence patient satisfaction after LAS for lumbar degenerative spondylolisthesis. These include a lower preoperative SF-36 general health, higher preoperative NPRS leg pain score, and a longer duration of surgery.

A lower preoperative SF-36 general health score may suggest that the patient has poorer baseline psychofunction. Gunzburg et al. ${ }^{37}$ studied patients 


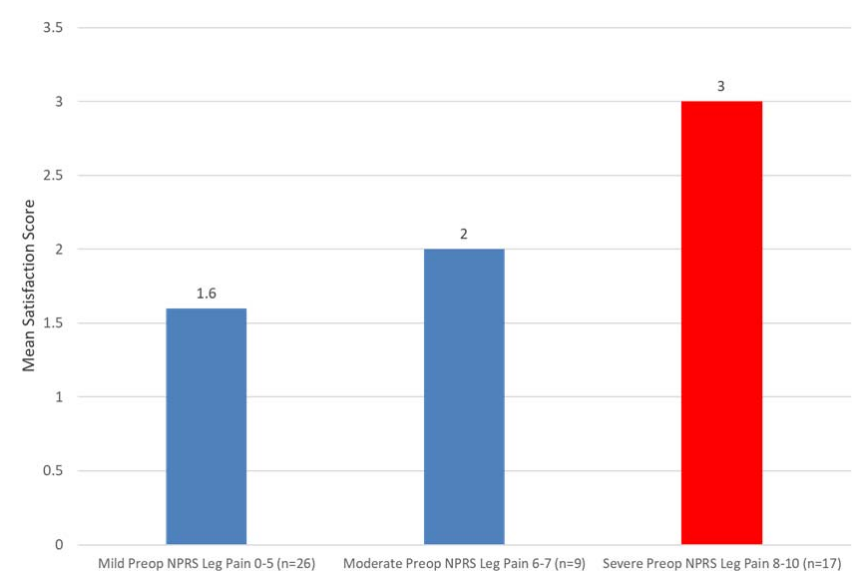

Figure 2. Preoperative Numerical Pain Rating Scale leg pain and satisfaction.

undergoing decompression surgery for lumbar spine stenosis and reported that better self-rated health was a positive predictor for treatment satisfaction, better ambulatory capacity, and reduced severity of radicular symptoms. This finding corresponds to our study results and highlights the potential poorer postoperative outcome in patients with lower baseline health-related quality-of-life scores.

The effect of NPRS leg pain score on patient satisfaction postoperatively could be multifactorial. Extent of nerve compression and reversibility of nerve damage causing radiculopathy and leg pain often cannot be determined, and indirect decompression from LAS may only be able to prevent further progression of disease, thus affecting patients' expectations and therefore satisfaction after operation. In our study, a higher preoperative NPRS leg pain score predicted lower postoperative satisfaction, suggesting that indirect decompression via LAS alone may not completely relieve the patient's symptoms. It is also plausible that patients with severe leg pain may not completely get symptom resolution through indirect decompression

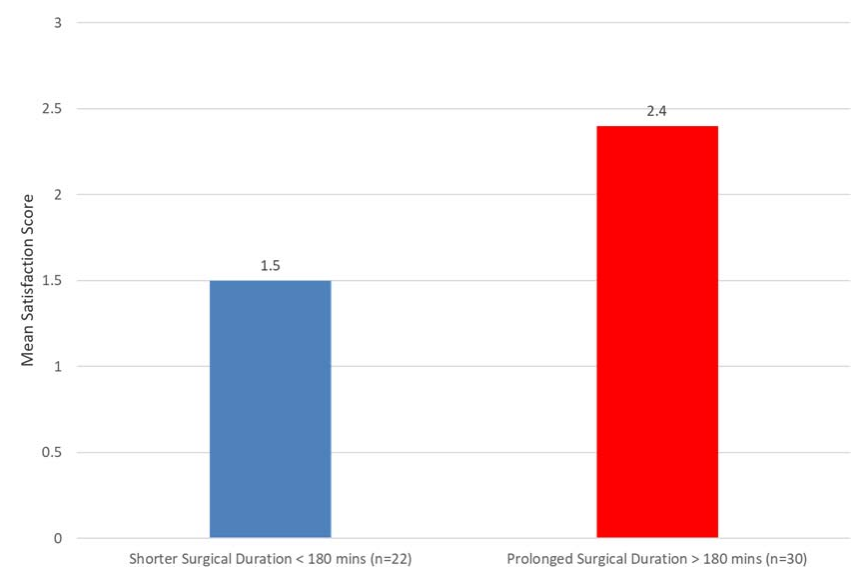

Figure 3. Surgical duration and satisfaction.

and therefore experienced lower satisfaction. Surgeons may consider supplementary direct decompression in these patients. In addition, patients with more levels of spinal stenosis are more likely to report neurogenic claudication symptoms,${ }^{38}$ which could affect their perceived leg pain score. Multileveled stenosis itself would also lead to a longer surgical duration which, in part, affects clinical outcomes.

Surgical duration is an important quality metric in the performance of lumbar fusion. After adjusting for multiple confounders, Kim et al. ${ }^{39}$ found that, in patients who underwent single-level lumbar fusion, those whose operative duration was longer were at heightened risk for various complications compared to patients with shorter duration of surgery. These include superficial site infection, organ/space site infection, wound dehiscence, deep vein thrombosis, and sepsis/septic shock. This in turn would lead to lower satisfaction rate after surgery. Since this is a single-center study with all operations performed by the same surgeon, a longer duration of surgery could also correlate with

Table 3. Radiological outcomes.

\begin{tabular}{|c|c|c|c|c|}
\hline Variable & Preoperative $(n=52)$ & 6 Month $(\mathrm{n}=52)$ & 2 Years $(n=52)$ & $P$ Value \\
\hline Cobb angle $\left(^{\circ}\right)$ & $9.1 \pm 8.3$ & $5.6 \pm 5.5$ & $6.0 \pm 6.2$ & $.023^{\mathrm{a}}$ \\
\hline Global lumbar lordosis $\left(^{\circ}\right)$ & $29.8 \pm 15.0$ & $34.6 \pm 10.5$ & $34.2 \pm 10.6$ & .11 (n.s.) \\
\hline Mean disc heights $(\mathrm{mm})$ & $6.9 \pm 2.2$ & $11.3 \pm 2.0$ & $10.6 \pm 2.3$ & $<.001$ \\
\hline Mean adjacent disc heights (mm) & $8.2 \pm 1.8$ & $9.3 \pm 3.2$ & $8.2 \pm 2.2$ & .05 (n.s.) \\
\hline \multirow[t]{4}{*}{ Bridwell fusion grade } & & & $98 \%$ Grade I & \\
\hline & & & $2 \%$ Grade II & \\
\hline & & & $0 \%$ Grade III & \\
\hline & & & $0 \%$ Grade IV & \\
\hline \multirow[t]{4}{*}{ Marchi subsidence grade } & & & $30.7 \%(16 / 52)$ Grade 0 & \\
\hline & & & $50 \%(26 / 52)$ Grade I & \\
\hline & & & $13.5 \%(7 / 52)$ Grade II & \\
\hline & & & $5.8 \%(3 / 52)$ Grade III & \\
\hline
\end{tabular}

Abbreviation: n.s., not significant.

${ }^{a}$ Boldface denotes values with statistical significance $(P<.05)$. 
multilevel disease or severe diseases that are more technically challenging, which by itself can affect patients' outcomes and satisfaction after surgery.

Patient education prior to surgery can have a positive impact on patient satisfaction. ${ }^{40}$ Identifying preoperative prognostic factors can potentially assist clinicians in their assessment of prognosis of a patient when considering surgical treatment. This can also help clinicians in counseling patients before operation and managing patients' expectations of an operation to achieve better satisfaction postoperatively. Few studies have attempted to identify potential prognostic factors influencing patients' postoperative clinical outcomes after spine surgery. However, this is often difficult due to the large number of variables, such as patient demographics, comorbidities, symptoms, and socioeconomic status, that can be studied. The predictive value may also be outcome specific; thus, preoperative factors influencing one aspect of clinical outcome might not necessary affect another. A systemic review by Aalto et al. ${ }^{24}$ attempted to identify predictors for postoperative clinical outcome in lumbar spinal stenosis, and due to the various type of predictors studied in each paper and the different outcome measures used by the different authors, of the 28 studies analyzed, only patient reported preoperative walking capacity predicting better postoperative capacity was identified in 2 of the studies. There is also a paucity of studies that specifically look at prognostic factor for a specific surgical technique rather than the outcome of a specific disease.

Radiological outcomes were not correlated with satisfaction in our study. Theoretically, cage subsidence and inability to maintain mean DH would lead to recompression of exiting nerve roots, negatively affecting patient outcomes. However, Marchi et al. demonstrated that radiographic cage subsidence did not adversely influence patient outcomes in the short term at 12 month follow up. ${ }^{34}$ Similarly, despite $70 \%$ of patients demonstrating cage subsidence in our study, patients still reported high satisfaction rates of $90 \%$.

The strength of this study is that this is a singleinstitute study where all patients were operated by a single surgeon with the same type of implant. This ensures consistency of decision making and surgical technique. All patients also received standard postoperative rehabilitation protocols. This allowed us to minimize any other external factors which could account for the deferring patient outcomes.
An extensive battery of standardized clinical, patient-reported and health-related outcomes, as well as radiological parameters was also examined.

This study has to be interpreted in light of its potential limitations. Firstly, this is a retrospective review of prospectively collected data. Future larger, randomized control trials will be required to further validate our findings. Secondly, there are a small number of patients in our study, as this is a pilot study of the LAS cases performed at our institution. A relatively low number of lateral access surgeries were performed per year at our institution. However, despite the small number of cases performed, the majority of patients attained high satisfaction, suggesting that LAS has a comparatively lower learning curve. Thirdly, patients with longer surgical durations may have undergone multiple-level surgery, which may, in part, contribute to poorer satisfaction. Upon stratified analysis, the patients with increased number of levels had higher scores, albeit nonsignificant $(P=.29)$. We acknowledge that a larger sample size may allow us to ascertain the effect of other potential cofounders, such as the number of levels operated on. A single surgeon may lead to selection bias. However, singlesurgeon studies ensure consistency and reproducibility of the technique, which may not occur in multisurgeon studies. In addition, all surgeries were performed by a spine surgeon who is experienced in the lateral access technique. Lastly, the duration of follow up is relatively short at 2 years, with no data to determine long-term satisfaction rate.

\section{CONCLUSIONS}

LAS is a viable treatment for adult lumbar degenerative spondylolisthesis with significant improvements in clinical outcomes and high rates of satisfaction, similar to previously published literature. Lower preoperative SF-36 general health scores, higher NPRS leg pain score, and longer surgical duration were identified as potential negative predictors of postoperative satisfaction. Identifying preoperative predictors for postoperative clinical outcome is necessary to assist clinicians in patient education prior to operation. This study provides valuable information regarding patient selection for LAS and reiterates the need for counseling in certain at-risk patient groups. More in-depth studies with larger sample sizes and longer follow up are needed to identify other potential 
predictors that may affect long-term patient satisfaction after LAS.

\section{REFERENCES}

1. Arnold PM, Anderson KK, McGuire RA Jr. The lateral transpsoas approach to the lumbar and thoracic spine: a review. Surg Neurol Int. 2012;3(Suppl 3):S198.

2. Pimenta L. Lateral endoscopic transpsoas retroperitoneal approach for lumbar spine surgery: VIII Brazilian Spine Society Meeting. Belo Horizonte, Minas Gerais, Brazil. 2001.

3. Ozgur BM, Aryan HE, Pimenta L, Taylor WR. Extreme lateral interbody fusion (XLIF): a novel surgical technique for anterior lumbar interbody fusion. Spine J. 2006;6(4):435-443.

4. Baker JK, Reardon PR, Reardon MJ, Heggeness MH. Vascular injury in anterior lumbar surgery. Spine (Phila $\mathrm{Pa}$ 1976). 1993;18(15):2227-2230.

5. Lindley EM, McBeth Z, Henry SE, Burger EL, Cain CM, Patel VV. Retrograde ejaculation following anterior lumbar spine surgery. Spine J. 2012;12(9):S135.

6. Than KD, Wang AC, Rahman SU, et al. Complication avoidance and management in anterior lumbar interbody fusion. Neurosurg Focus. 2011;31(4):E6.

7. Rihn JA, Patel R, Makda J, et al. Complications associated with single-level transforaminal lumbar interbody fusion. Spine J. 2009;9(8):623-629.

8. Okuda S, Miyauchi A, Oda T, Haku T, Yamamoto T, Iwasaki M. Surgical complications of posterior lumbar interbody fusion with total facetectomy in 251 patients. $J$ Neurosurg Spine. 2006;4(4):304-309.

9. Mehta VA, McGirt MJ, Garcés Ambrossi GL, et al. Trans-foraminal versus posterior lumbar interbody fusion: comparison of surgical morbidity. Neurolog Res. 2011;33(1):38-42.

10. Davne SH, Myers DL. Complications of lumbar spinal fusion with transpedicular instrumentation. Spine (Phila $\mathrm{Pa}$ 1976). 1992;17(6 Suppl):S184-S189.

11. Deluzio KJ, Lucio JC, Rodgers WB. Value and cost in less invasive spinal fusion surgery: lessons from a community hospital. SAS J. 2010;4(2):37-40.

12. Rodgers WB, Gerber EJ, Patterson J. Intraoperative and early postoperative complications in extreme lateral interbody fusion: an analysis of 600 cases. Spine (Phila Pa 1976). 2011;36(1):26-32.

13. Youssef JA, McAfee PC, Patty CA, et al. Minimally invasive surgery: lateral approach interbody fusion: results and review. Spine (Phila Pa 1976). 2010;35(26S):S302-S311.

14. Bergey DL, Villavicencio AT, Goldstein T, Regan JJ. Endoscopic lateral transpsoas approach to the lumbar spine. Spine (Phila Pa 1976). 2004;29(15):1681-1688.

15. Rodgers WB, Cox CS, Gerber EJ. Early complications of extreme lateral interbody fusion in the obese. Clin Spine Surg. 2010;23(6):393-397.

16. Karikari IO, Grossi PM, Nimjee SM, et al. Minimally invasive lumbar interbody fusion in patients older than 70 years of age: analysis of peri- and postoperative complications. Neurosurgery. 2011;68(4):897-902.

17. Anand N, Baron EM, Thaiyananthan G, Khalsa K, Goldstein TB. Minimally invasive multilevel percutaneous correction and fusion for adult lumbar degenerative scoliosis: a technique and feasibility study. Clin Spine Surg. 2008;21(7):459-467.

18. Dakwar E, Cardona RF, Smith DA, Uribe JS. Early outcomes and safety of the minimally invasive, lateral retroperitoneal transpsoas approach for adult degenerative scoliosis. Neurosurg Focus. 2010;28(3):E8.

19. Wang MY, Mummaneni PV. Minimally invasive surgery for thoracolumbar spinal deformity: initial clinical experience with clinical and radiographic outcomes. Neurosurg Focus. 2010;28(3):E9.

20. Acosta FL Jr, Liu J, Slimack N, Moller D, Fessler R, Koski T. Changes in coronal and sagittal plane alignment following minimally invasive direct lateral interbody fusion for the treatment of degenerative lumbar disease in adults: a radiographic study. J Neurosurg Spine. 2011;15(1):92-96.

21. Karikari IO, Nimjee SM, Hardin CA, et al. Extreme lateral interbody fusion approach for isolated thoracic and thoracolumbar spine diseases: initial clinical experience and early outcomes. Clin Spine Surg. 2011;24(6):368-375.

22. Khajavi K, Shen A, Lagina M, Hutchison A. Comparison of clinical outcomes following minimally invasive lateral interbody fusion stratified by preoperative diagnosis. Eur Spine J. 2015;24(3):322-330.

23. Knight RQ, Schwaegler P, Hanscom D, Roh J. Direct lateral lumbar interbody fusion for degenerative conditions: early complication profile. Clin Spine Surg. 2009;22(1):34-37.

24. Rodgers WB, Gerber EJ, Patterson J. Intraoperative and early postoperative complications in extreme lateral interbody fusion: an analysis of 600 cases. Spine (Phila Pa 1976). 2011;36(1):26-32.

25. Kaiser MG, Haid RW Jr, Subach BR, Miller JS, Smith CD, Rodts GE Jr. Comparison of the mini-open versus laparoscopic approach for anterior lumbar interbody fusion: a retrospective review. Neurosurgery. 2002;51(1):97-105.

26. Zdeblick TA, David SM. A prospective comparison of surgical approach for anterior L4-L5 fusion: laparoscopic versus mini anterior lumbar interbody fusion. Spine (Phila Pa 1976). 2000;25(20):2682-2687.

27. Aalto TJ, Malmivaara A, Kovacs F, et al. Preoperative predictors for postoperative clinical outcome in lumbar spinal stenosis: systematic review. Spine (Phila Pa 1976). 2006;31(18):E648-E663.

28. Airaksinen O, Herno A, Turunen V, Saari T, Suomlainen O. Surgical outcome of 438 patients treated surgically for lumbar spinal stenosis. Spine (Phila Pa 1976). 1997;22(19):2278-2282.

29. Ferraz MB, Quaresma MR, Aquino LR, Atra E, Tugwell P, Goldsmith $\mathrm{CH}$. Reliability of pain scales in the assessment of literate and illiterate patients with rheumatoid arthritis. J Rheumatol. 1990;17(8):1022-1024.

30. Williams AC, Davies HT, Chadury Y. Simple pain rating scales hide complex idiosyncratic meanings. Pain. 2000;85(3):457-463.

31. Grönblad M, Hupli M, Wennerstrand $P$, et al. Intercorrelation and test-retest reliability of the Pain Disability Index (PDI) and the Oswestry Disability Questionnaire (ODQ) and their correlation with pain intensity in low back pain patients. Clin J Pain. 1993;9(3):189-195.

32. Fisher K, Johnston M. Validation of the Oswestry low back pain disability questionnaire, its sensitivity as a measure of change following treatment and its relationship with other 
aspects of the chronic pain experience. Physiother Theory Pract. 1997;13(1):67-80.

33. Roland M, Morris R. A study of the natural history of back pain. Part I: development of a reliable and sensitive measure of disability in low-back pain. Spine (Phila Pa 1976). 1983;8(2):141-144.

34. Marchi L, Abdala N, Oliveira L, Amaral R, Coutinho E, Pimenta L. Radiographic and clinical evaluation of cage subsidence after stand-alone lateral interbody fusion. $J$ Neurosurg Spine. 2013;19(1):110-118.

35. Bridwell KH, Lenke LG, McEnery KW, Baldus C, Blanke K. Anterior fresh frozen structural allografts in the thoracic and lumbar spine. Do they work if combined with posterior fusion and instrumentation in adult patients with kyphosis or anterior column defects? Spine (Phila Pa 1976). 1995;20(12):1410-1418.

36. Copay AG, Glassman SD, Subach BR, Berven S, Schuler TC, Carreon LY. Minimum clinically important difference in lumbar spine surgery patients: a choice of methods using the Oswestry Disability Index, Medical Outcomes Study questionnaire Short Form 36, and pain scales. Spine J. 2008;8(6):968-974.

37. Gunzburg R, Keller T, Szpalski M, Vandeputte K, Spratt K. Clinical and psychofunctional measures of conservative decompression surgery for lumbar spinal stenosis: a prospective cohort study. Eur Spine J. 2003;12(2):197-204.

38. Park DK, An HS, Lurie JD, et al. Does multilevel lumbar stenosis lead to poorer outcomes? A subanalysis of the SPORT lumbar stenosis study. Spine (Phila Pa 1976). 2010;35(4):439.
39. Kim BD, Hsu WK, De Oliveira GS Jr, Saha S, Kim JY. Operative duration as an independent risk factor for postoperative complications in single-level lumbar fusion: an analysis of 4588 surgical cases. Spine (Phila Pa 1976). 2014;39(6):510 520 .

40. Papanastassiou I, Anderson R, Barber N, Conover C, Castellvi AE. Effects of preoperative education on spinal surgery patients. Int J Spine Surg. 2011;5(4):120-124.

Disclosures and COI: The authors of this manuscript have nothing to disclose that would bias our work. Local institutional review board waiver was obtained for this study.

Corresponding Author: Sheng Xu, MBBS, MRCS, Department of Orthopaedic Surgery, Singapore General Hospital, 20 College Road, Academia, Level 4. Singapore 169865. Phone: +65 81282418; Email: sheng.xu@mohh.com.sg.

Published 31 October 2019

This manuscript is generously published free of charge by ISASS, the International Society for the Advancement of Spine Surgery. Copyright (c) 2019 ISASS. To see more or order reprints or permissions, see http://ijssurgery.com. 